\title{
Original
}

\section{Safety and Efficacy of Adenosine 5'-Triphosphate as a Hyperemic Agent for the Assessment of Peripheral Fractional Flow Reserve}

\author{
Atsuo MaedA ${ }^{1,2)}$, Kazuma Tashiro ${ }^{1)}$, Masahiro SASAi ${ }^{1)}$, \\ Hiroyoshi Mori ${ }^{1)}$, Tokutada SATO ${ }^{1)}$, Munetaka HAYASHI ${ }^{2)}$ \\ and Hiroshi SUZUKI ${ }^{* 1)}$
}

\begin{abstract}
The myocardial fractional flow reserve (FFR) is a useful measure of physiological stenosis in the coronary artery. Previous reports have identified peripheral FFR (pFFR) as another useful measure in peripheral artery disease (PAD) ; however, the vasodilators used to obtain maximal hyperemia varied among studies. The present study was conducted to identify the ideal vasodilator and vasodilator dose for pFFR assessment. We enrolled 24 patients with 26 lesions, comprising 14 lesions of the iliac artery and 12 lesions of the superficial femoral artery (SFA). After measuring the mean aortic pressure $(\mathrm{Pa})$, the guidewire was advanced across the lesion and the mean distal pressure $(\mathrm{Pd})$ was measured at the baseline $\mathrm{Pd} / \mathrm{Pa}$. A 100- $\mathrm{g}$ dose of adenosine 5'-triphosphate (ATP) was then administered to obtain a pFFR with a washout interval of 5 to 10 minutes. Next, $200 \mu \mathrm{g}$ of ATP, $10 \mathrm{mg}$ of papaverine hydrochloride, or $1.5 \mathrm{mg}$ of isosorbide dinitrate was administered before the final pFFR measurement. The baseline $\mathrm{Pd} / \mathrm{Pa}(0.88$ $\pm 0.08)$ was significantly decreased after each vasodilator $(P<0.0001)$, but there was no significant difference in pFFR among vasodilators $(P=0.7569)$. The study was discontinued in two patients with SFA lesions due to decreased systemic blood pressure after vasodilator administration. The hyperemic efficacy of $100 \mu \mathrm{g}$ of ATP administered intra-arterially was similar to the efficacies of $200 \mu \mathrm{g}$ of ATP, $10 \mathrm{mg}$ of papaverine hydrochloride, and $1.5 \mathrm{mg}$ of isosorbide dinitrate. Given the milder side effects of ATP versus other vasodilators, an intra-arterial dose of ATP $100 \mu \mathrm{g}$ may be optimal as a first-line agent for pFFR measurement.
\end{abstract}

Key words : peripheral artery disease, endovascular treatment, fractional flow reserve, physiological stenosis, adenosine 5'-triphosphate

\section{Introduction}

Stent implantation has improved the initial and long-term outcomes of endovascular treatment (EVT) in both the iliac artery and superficial femoral artery (SFA) in patients with peripheral

\footnotetext{
1) Department of Medicine, Division of Cardiology, Showa University Fujigaoka Hospital, 1-30 Fujigaoka, Aoba-ku, Yokohama City, Kanagawa 227-8501, Japan.

2) Department of Emergency and Disaster Medicine, Showa University Fujigaoka Hospital.

* To whom corresponding should be addressed.
} 
artery disease (PAD). The TASC II guidelines recommend EVT for TASC A- \& B-type lesions, which show short- or middle-length stenosis and short chronic total occlusion ${ }^{1)}$. While the ankle brachial index $(\mathrm{ABI})$ and exercise $\mathrm{ABI}$ are established measures to evaluate ischemia in the whole limb of PAD patients, evaluating culprit lesions is sometimes very difficult in patients with multiple lesions or angiographically moderate stenotic lesions. EVT for non-significant stenotic lesions confers no symptomatic improvement and can induce harmful events.

The fractional flow reserve (FFR) is an established measure for estimating physiological stenosis in coronary artery disease ${ }^{2)}$. The measurement and assessment of myocardium FFR is a useful procedure for reducing the rate of major adverse cardiovascular events in percutaneous coronary intervention $(\mathrm{PCI})^{3)}$. Vasodilator administration to maximize hyperemia of the myocardium is key to the correct measurement of FFR. In coronary artery disease, intracoronary papaverine and intravenous adenosine 5'-triphosphate (ATP) are usually administered as vasodilators to induce maximal hyperemia when assessing diffuse coronary atherosclerosis ${ }^{4)}$.

In contrast, the EVT guidelines ${ }^{1,5)}$ recommend pressure measurements across lesions both at rest and during hyperemia induction in cases with unclear hemodynamic significance of the target lesion. At the same time, several reports ${ }^{6-15)}$ have advocated peripheral FFR ( $\mathrm{pFFR}$ ) for evaluating the significance of stenosis versus that of peak systolic pressure or catheter-derived pressure gradients; however the vasodilators used varied among these studies, and there is no standard vasodilator defined for obtaining maximal hyperemia. The present study thus sought to identify the ideal vasodilator and dose for measuring pFFR without side effects.

\section{Methods}

\section{Patient population}

This investigation was a retrospective, single center study conducted at Showa University Fujigaoka Hospital including adult patients ( $>20$ years of age) with intermittent claudication or critical limb ischemia who underwent lower extremity artery echo or enhanced computed tomography. Patients suspected of having significant stenosis of the iliac artery or SFA underwent EVT. In cases of moderate stenosis, pFFR was performed to judge whether it is significant stenosis or not. Patients with acute limb ischemia, TASC II type C or D lesions, no patent arteries below the knee, or lesions with more than $90 \%$ stenosis on angiography were excluded from this study. TASC II C \& D lesions were defined as those with long or multiple stenosis and long chronic total occlusion with or without calcification. The 24 patients (26 lesions) who met the inclusion criteria were enrolled in the study from January 2012 to December 2016.

The institutional review board of our hospital approved the study protocol, and all patients provided informed consent.

\section{pFFR measurement}

EVT was performed under local anesthesia using a 4 or 6 French (Fr) guiding sheath (Parent Plus $^{\circledR}$, Medikit, Tokyo, Japan) for treatment introduced via the ipsilateral approach or a $6 \mathrm{Fr}$ 

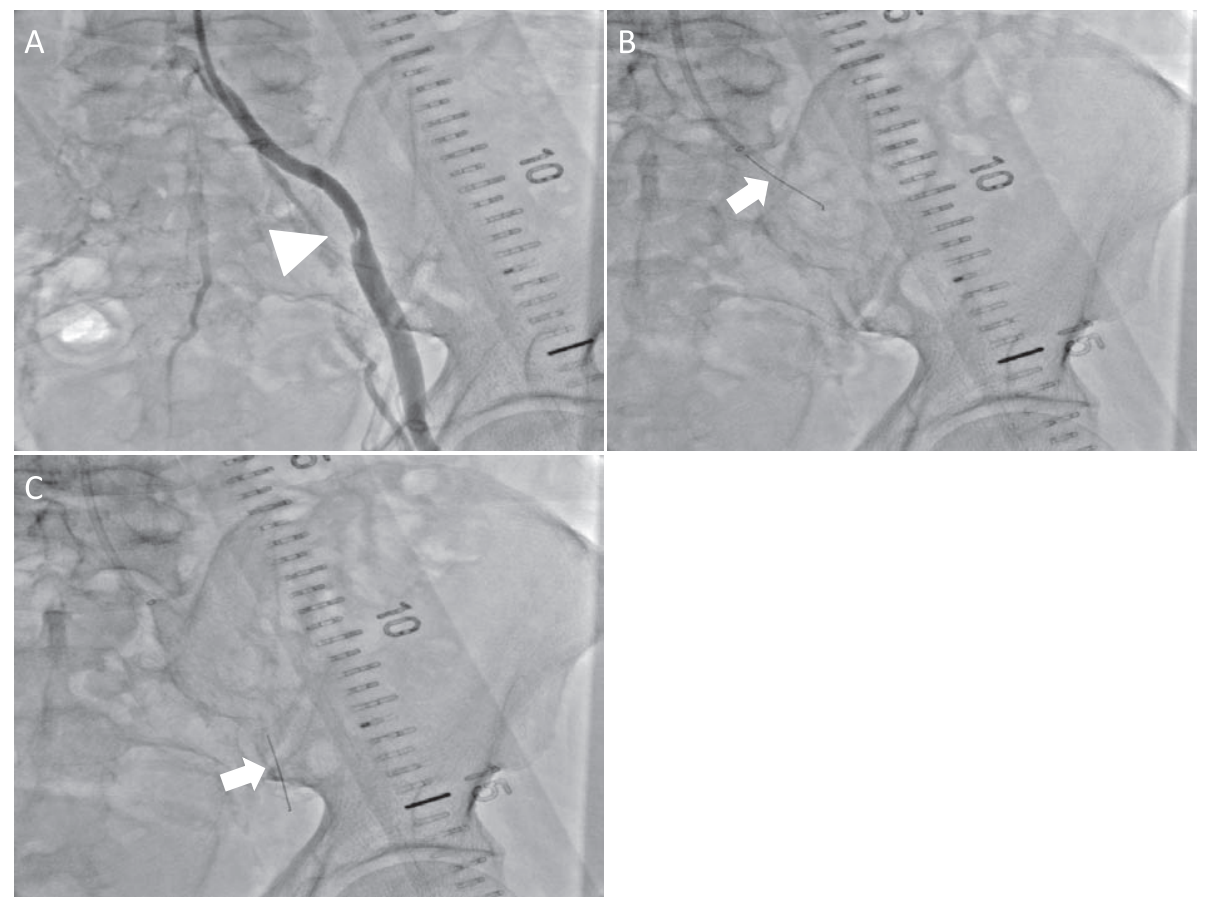

Fig. 1. pFFR measurement of a mildly stenotic lesion in the left external iliac artery A: The delta shows mild stenosis of the left external iliac artery.

$\mathrm{B}$ : The pressure guidewire at the distal tip of the guide sheath measures the mean aortic pressure (arrow).

$\mathrm{C}$ : The pressure guidewire at the distal tip of the stenosis lesion measures the mean distal pressure (arrow).

pFFR, fractional flow reserve in peripheral artery disease.

guiding sheath (Destination ${ }^{\circledR}$, Terumo, Tokyo, Japan) introduced via the contralateral approach.

All patients received intravenous heparin $(5000 \mathrm{U})$ administration prior to placement of the guidewire. After confirming 50-75\% stenosis of either the iliac artery or SFA by peripheral angiography, the tip of the guiding sheath was confirmed to be at a position where the peripheral blood flow was left undisturbed. A 0.014" pressure guidewire (St. Jude Medical, St. Paul, MN, USA) was advanced to the distal tip of the guiding sheath, the pressure was equalized, and then the mean aortic pressure $(\mathrm{Pa})$ was measured after a 5 to $10-\mathrm{ml}$ saline flush to remove contrast agent in the catheter. The guidewire was then advanced across the lesion for measuring the mean distal pressure (Pd) at baseline $\mathrm{Pd} / \mathrm{Pa}$ (Fig. 1).

The optimal dose of papaverine hydrochloride for inducing maximum hyperemia was assessed in a preliminary investigation, as different doses of the agent were used in previous studies ${ }^{9,10,16)}$. Hyperemia was induced with $10 \mathrm{mg}$ of papaverine hydrochloride, the $\mathrm{Pa}$ and $\mathrm{Pd}$ measurements were repeated, and then pFFR was calculated as the ratio of mean Pd to mean Pa during hyperemia. While the pFFR thus calculated increased to $20 \mathrm{mg}$ and $30 \mathrm{mg}$ with a washout interval of 5 to 10 minutes between subsequent administrations, no significant difference in pFFR was found at different doses (Fig. 2). Therefore, the optimal papaverine hydrochloride dose for inducing hyperemia in this study was defined as $10 \mathrm{mg}$. 


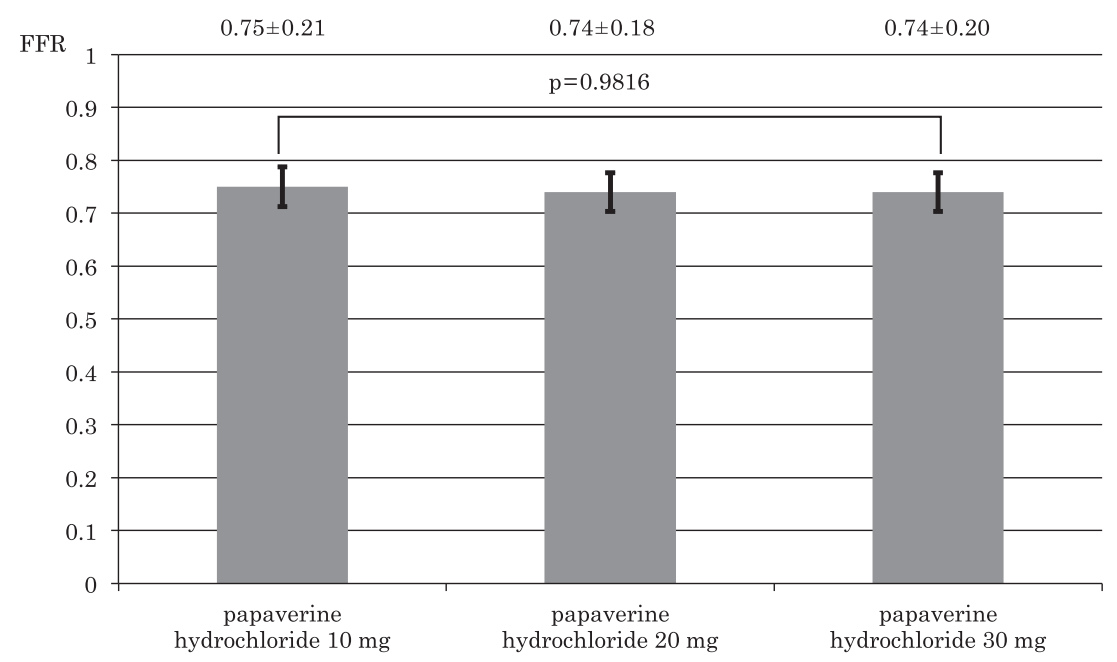

Fig. 2. pFFR following each papaverine hydrochloride dose (8 lesions). pFFR, fractional flow reserve in peripheral artery disease.

Three vasodilators were compared in the present study: $\operatorname{ATP}^{7,10)}$, papaverine hydrochloride ${ }^{8-10,14)}$, and isosorbide dinitrate. First, $100 \mu \mathrm{g}$ of ATP was administered from the guiding sheath to determine the pFFR with a washout interval of 5 to 10 minutes. After confirming complete recovery to the baseline pFFR, $200 \mu \mathrm{g}$ of ATP was administered. The same procedures were repeated after administration of $10 \mathrm{mg}$ of papaverine hydrochloride and $1.5 \mathrm{mg}$ of isosorbide dinitrate.

\section{Statistical analysis}

Continuous variables are expressed as means \pm standard deviations and categorical variables are reported as percentages. Variable comparisons between groups were conducted using ANOVA $\&$ post hoc tests for continuous variables and Fisher's exact test for categorical variables. All analyses were performed using JMP software version 12 (SAS Institute Inc., Cary, NC, USA).

\section{Results}

\section{Baseline characteristics}

Table 1 details the characteristics of patients enrolled in this study. The patients had a mean age of $77 \pm 1$ (range 60-95) years and 18 patients were male (75.0\%). Twenty patients (81.0\%) had intermittent claudication and four (19.0\%) had critical limb ischemia. Table 2 shows the types of lesions and procedures used. Of the 26 lesions, 14 (53.8\%) were located in the SFA and $12(46.2 \%)$ were located in the iliac artery; $7(26.9 \%)$ lesions underwent balloon angioplasty, $17(65.4 \%)$ underwent stent placement, and $2(7.7 \%)$ were deferred for EVT based on the pFFR results.

\section{Effects of each vasodilator}

Figure 3 shows the baseline $\mathrm{Pd} / \mathrm{Pa}$ and pFFR results for the vasodilators examined. The 
Table 1. Patient characteristics (26 lesions and 24 patients)

\begin{tabular}{|c|c|}
\hline Variable & \\
\hline Age, years & $77 \pm 1$ \\
\hline Sex, male $(\%)$ & $18(75.0)$ \\
\hline BMI, $\mathrm{kg} / \mathrm{m}^{2}$ & $21.2 \pm 5.0$ \\
\hline Hypertension (\%) & $20(83.3)$ \\
\hline Diabetes mellitus (\%) & $8(33.3)$ \\
\hline Insulin use $(\%)$ & $2(8.3)$ \\
\hline Dyslipidemia（\%) & $16(66.7)$ \\
\hline Current smoker (\%) & $5(20.8)$ \\
\hline Past smoker $(\%)$ & $9(37.5)$ \\
\hline Coronary artery disease (\%) & $13(54.2)$ \\
\hline Cerebral vascular disease $(\%)$ & $2(8.3)$ \\
\hline Hemodialysis (\%) & $4(16.7)$ \\
\hline \multicolumn{2}{|l|}{ Clinical presentation } \\
\hline Intermittent claudication (\%) & $20(81.0)$ \\
\hline Critical limb ischemia (\%) & $4(19.0)$ \\
\hline \multicolumn{2}{|l|}{ Fontaine } \\
\hline I $(\%)$ & $0 \quad(0)$ \\
\hline II $(\%)$ & $20(81.0)$ \\
\hline III $(\%)$ & $0 \quad(0)$ \\
\hline IV $(\%)$ & $4(19.0)$ \\
\hline \multicolumn{2}{|l|}{ Rutherfold } \\
\hline $1(\%)$ & $0 \quad(0)$ \\
\hline $2(\%)$ & $9(28.6)$ \\
\hline $3(\%)$ & $11(52.4)$ \\
\hline $4(\%)$ & $\begin{array}{ll}0 \quad(0.0) & 0\end{array}$ \\
\hline $5(\%)$ & $4(19.0)$ \\
\hline $6(\%)$ & 0 \\
\hline \multicolumn{2}{|l|}{ Medications } \\
\hline Aspirin (\%) & $15(62.5)$ \\
\hline Clopidogrel (\%) & $12(50.0)$ \\
\hline Cilostazol $(\%)$ & $8(32.3)$ \\
\hline Sarpogrelate $(\%)$ & $4(16.7)$ \\
\hline Statin $(\%)$ & $10(41.7)$ \\
\hline $\mathrm{ACE} / \mathrm{ARB}(\%)$ & $11(45.8)$ \\
\hline Ca blocker (\%) & $10(41.7)$ \\
\hline$\beta$-blocker (\%) & $4(16.7)$ \\
\hline
\end{tabular}

ACE : Angiotensin converting enzyme inhibitor ARB : Angiotensin II receptor blocker
Table 2. Characteristics of the lesions and procedures used (26 lesions)

\begin{tabular}{|c|c|}
\hline Variable & \\
\hline \multicolumn{2}{|l|}{ Lesion characteristics } \\
\hline SFA $(\%)$ & $14(53.8)$ \\
\hline Iliac $(\%)$ & $12(46.2)$ \\
\hline \multicolumn{2}{|l|}{ TASC classification } \\
\hline A $(\%)$ & $14(53.8)$ \\
\hline B (\%) & $12(46.2)$ \\
\hline Restenosis（\%) & $2 \quad(7.7)$ \\
\hline Vessel calcification (\%) & $10(41.7)$ \\
\hline \multicolumn{2}{|l|}{ Interventional results } \\
\hline POBA（\%) & $7(26.9)$ \\
\hline STENT（\%) & $17(65.4)$ \\
\hline Deferred $(\%)$ & $2 \quad(7.7)$ \\
\hline Number of stents & $1.1 \pm 0.3$ \\
\hline Total stent length $(\mathrm{mm})$ & $45.3 \pm 14.9$ \\
\hline Mean stent diameter $(\mathrm{mm})$ & $7.7 \pm 1.0$ \\
\hline \multicolumn{2}{|l|}{ Number of run-off vessels } \\
\hline $0(\%)$ & $1 \quad(3.8)$ \\
\hline $1(\%)$ & $6(23.1)$ \\
\hline $2(\%)$ & $10(38.5)$ \\
\hline $3(\%)$ & $9(34.6)$ \\
\hline
\end{tabular}

TASC: TransAtlantic InterSociety Consensus SFA : Superficial femoral artery

POBA : Plain old balloon angiography

baseline $\mathrm{Pd} / \mathrm{Pa}(0.88 \pm 0.08)$ decreased significantly after the use of every vasodilator $(P<$ $0.0001)$, but there was no significant difference in the level of decrease among the vasodilators $(P=0.7569)$. 


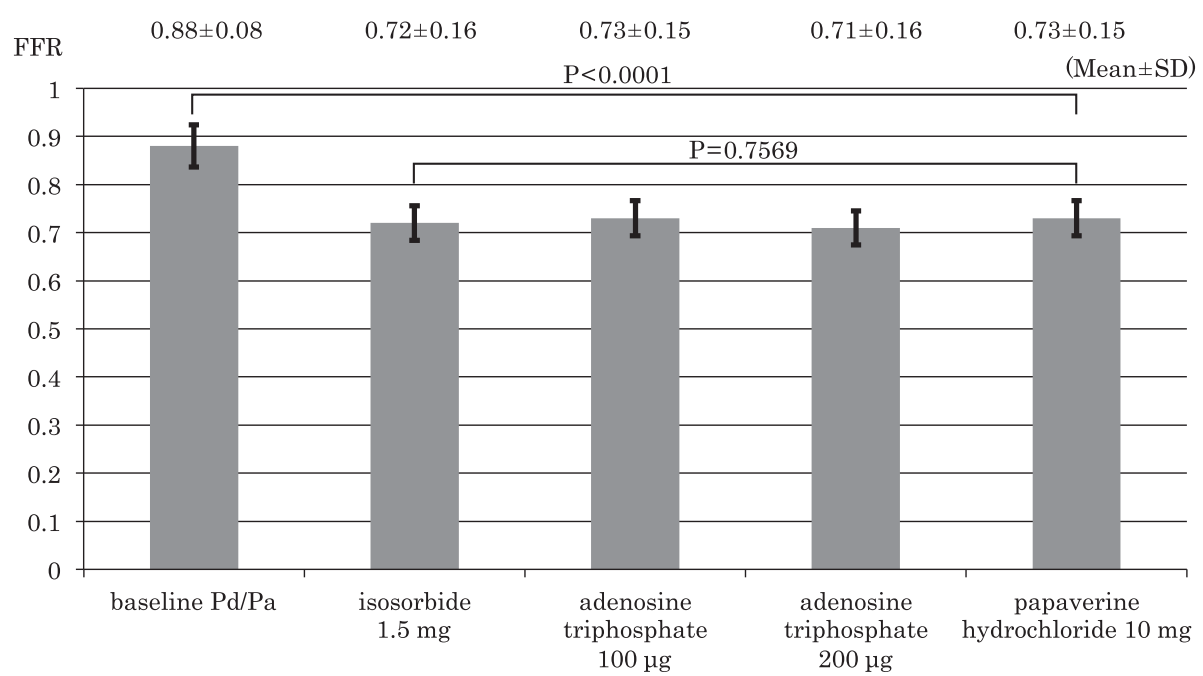

Fig. 3. Baseline $\mathrm{Pd} / \mathrm{Pa}$ and pFFR obtained with each vasodilator (24 lesions) $\mathrm{Pd}$, mean distal pressure. Pa, mean aortic pressure. pFFR, fractional flow reserve in peripheral artery disease.

\section{Vasodilator side effects}

The study had to be discontinued in two patients with SFA lesions due to decreases in systemic blood pressure after vasodilator administration. In one case, the systolic blood pressure dropped to $60 \mathrm{mmHg}$ after the administration of $10 \mathrm{mg}$ papaverine hydrochloride, while in the other, the systolic blood pressure dropped to $58 \mathrm{mmHg}$ after the administration of $1.5 \mathrm{mg}$ isosorbide dinitrate.

\section{Discussion}

This is the first report comparing the effectiveness with which maximum hyperemia can be measured using various agents for the assessment of pFFR in PAD. The intra-arterial administration of ATP, papaverine chloride, and isosorbide dinitrate demonstrated similar effects in obtaining maximum hyperemia in pFFR, but the latter two agents induced systemic drops in blood pressure in two patients. Regarding the dose of ATP, a $100 \mu \mathrm{g}$ dose of ATP was effective in achieving maximum hyperemia.

The maximum blood flow reserve of skeletal muscle is greater than that of the myocardium ${ }^{11)}$; however, the muscle mass of the lower limbs varies much more between individuals compared to heart muscle, and the optimal vasodilator dose for obtaining maximum hyperemia depends on muscle mass ${ }^{12,13)}$. In addition, the degree to which a vasodilator expands a blood vessel might also differ from person to person. For these reasons, it is more difficult to determine the appropriate dose and type of vasodilator in pFFR than it is to measure FFR in PCI. Significant stenosis was traditionally defined physiologically as a mean arterial pressure difference greater than $10 \mathrm{mmHg}^{17)}$, although passing a catheter through a lesion also induces a pressure gradient, even when using a small catheter such as a 4 Fr. Thus, a 0.014-inch pressure wire is superior to a small-size catheter in assessing the actual pressure gradient induced ${ }^{6)}$. In the present study we 
confirmed that the tip of the guiding sheath was placed at a position where the peripheral blood flow was left undisturbed on peripheral angiography. If the systolic pressure of the catheter became lower than that of the brachial pressure, we moved the catheter to a more proximal position, but not to a degree that would result in any difference between the sites. Papaverine has been reported to induce potential side effects such as hypotension, variable patient response $^{16,18)}$, and serious arrhythmia ${ }^{19)}$. In addition, intra-coronary papaverine can prolong the QT interval, leading to polymorphic ventricular tachycardia and ventricular fibrillation. Although the mechanism underlying papaverine-induced QT prolongation is not fully understood, the drug can inhibit delayed rectifying potassium currents ( $\mathrm{IKr}$ ) and prolong the action potential duration. When the action potential duration is excessively prolonged, premature after-depolarization could provoke triggered activity and subsequent ventricular fibrillation ${ }^{19)}$. Approximately half of all PAD patients are complicated with ischemic heart disease, so precautions to protect patients from serious arrhythmias are imperative. Thus, this study had to be discontinued in two patients with SFA lesions because of decreases in systemic blood pressure after receiving $10 \mathrm{mg}$ of papaverine chloride or $1.5 \mathrm{mg}$ of isosorbide dinitrate. Two of four patients taking betablockers in this study were also discontinued due to a decrease in systemic blood pressure. The administration of adenosine triphosphate $100 \mu \mathrm{g}$ and $200 \mu \mathrm{g}$ elicited no such decrease. The very short half-life (1 to a few seconds) of ATP makes it a useful agent for repeated evaluations of ischemia in multiple arteries without side effects ${ }^{20)}$.

In this preliminary study we determined that a $10 \mathrm{mg}$ dose of papaverine hydrochloride was optimal for obtaining maximum hyperemia. The difference in the hyperemic dose of papaverine hydrochloride versus that was reported by Miki et $a l^{16)}$ may stem from differences in the target patients and vessels, as their study involved SFA lesions of normal subjects. Further, patients receiving papaverine hydrochloride have shown variable responses to the agent. Meanwhile, the $1.5 \mathrm{mg}$ dose set for isosorbide dinitrate was based on empirically administered amounts in Japan. Finally, we set the ATP dose at $100 \mu \mathrm{g}$ and $200 \mu \mathrm{g}$ in the present study, based on a dose of $1 \mu \mathrm{g} / \mathrm{kg}$ in an earlier study and $200 \mu \mathrm{g}$ in another study ${ }^{7,10)}$.

\section{Conclusions}

The hyperemic efficacy of the intra-arterial administration of $100 \mu \mathrm{g}$ of ATP was similar to the efficacies of $200 \mu \mathrm{g}$ of ATP, $10 \mathrm{mg}$ of papaverine hydrochloride, and $1.5 \mathrm{mg}$ of isosorbide dinitrate. Given the milder side effects of ATP versus other vasodilators, ATP at an intra-arterial dose of $100 \mu \mathrm{g}$ may be optimal as a first-line agent for pFFR measurement.

\section{Conflict of interest disclosure}

None.

\section{References}

1) Norgren L, Hiatt WR, Dormandy JA, et al. Inter-society consensus for the management of peripheral arterial disease (TASC II). J Vasc Surg. 2007;45 Suppl S:S5-S67. 
2) Pijls NH, De Bruyne B, Peels K, et al. Measurement of fractional flow reserve to assess the functional severity of coronary artery stenosis. N Engl J Med. 1996;334:1703-1708.

3) Tonino PA, De Bruyne B, Pijls NH, et al. Fractional flow reserve versus angiography for guiding percutaneous coronary intervention. N Engl J Med. 2009;360:213-224.

4) De Bruyne B, Pijls NH, Barbato E, et al. Intracoronary and intravenous adenosine 5'-triphosphate, adenosine, papaverine, and contrast medium to assess fractional flow reserve in humans. Circulation. 2003;107:1877-1883.

5) European Stroke Organisation, Tendera M, Aboyans V, et al. ESC guidelines on the diagnosis and treatment of peripheral artery diseases. Document covering atherosclerotic disease of extracranial carotid and vertebral, mesenteric, renal, upper and lower extremity arteries: the Task Force on the Diagnosis and Treatment of Peripheral Artery Diseases of the European Society of Cardiology (ESC). Eur Heart J. 2011;32:2851-2906.

6) Garcia LA, Carrozza JP Jr. Physiologic evaluation of translesion pressure gradients in peripheral arteries: comparison of pressure wire and catheter-derived measurements. J Interv Cardiol. 2007;20:63-65.

7) Lotfi AS, Sivalingam SK, Giugliano GR, et al. Use of fraction flow reserve to predict changes over time in management of superficial femoral artery. J Interv Cardiol. 2012;25:71-77.

8) Matsuno S, Yajima J, Oikawa Y, et al. Application of pressure wire for functional evaluation of angiographically inapparent external iliac artery stenosis: a case report. Jpn J Interv Cardiol. 2009;24:237-241. (in Japanese).

9) Kobayashi N, Hirano K, Nakano M, et al. Measuring procedure and maximal hyperemia in the assessment of fractional flow reserve for superficial femoral artery disease. J Atheroscler Thromb. 2016;23:56-66.

10) Cavendish JJ, Carter LI, Tsimikas S. Recent advances in hemodynamics: noncoronary applications of a pressure sensor angioplasty guidewire. Catheter Cardiovasc Interv. 2008;71:748-758.

11) Bragadeesh T, Sari I, Pascotto M, et al. Detection of peripheral vascular stenosis by assessing skeletal muscle flow reserve. J Am Coll Cardiol. 2005;45:780-785.

12) Lindner JR, Womack L, Barrett EJ, et al. Limb stress-rest perfusion imaging with contrast ultrasound for the assessment of peripheral arterial disease severity. JACC Cardiovasc Imaging. 2008;1:343-350.

13) Wu WC, Mohler E 3rd, Ratcliffe SJ, et al. Skeletal muscle microvascular flow in progressive peripheral artery disease: assessment with continuous arterial spin-labeling perfusion magnetic resonance imaging. J Am Coll Cardiol. 2009;53:2372-2377.

14) Hioki $\mathrm{H}$, Miyashita $\mathrm{Y}$, Miura $\mathrm{T}$, et al. Diagnostic value of peripheral fractional flow reserve in isolated iliac artery stenosis: a comparison with the post-exercise ankle-brachial index. $J$ Endovasc Ther. 2014;21:625-632.

15) Murata N, Aihara H, Soga Y, et al. Validation of pressure gradient and peripheral fractional flow reserve measured by a pressure wire for diagnosis of iliofemoral artery disease with intermediate stenosis. Med Devices (Auckl). 2015;8:467-472.

16) Miki K, Fujii K, Fukunaga M, et al. Assessment of lower limb flow and adequate intra-arterial papaverine doses to achieve maximal hyperemia in elder subjects. Cardiovasc Interv Ther. 2015;30:227-233.

17) Tetteroo E, Van Der Graaf Y, Bosch JL, et al. Randomised comparison of primary stent placement versus primary angioplasty followed by selective stent placement in patients with iliac artery occlusive disease. Dutch Iliac Stent Trial Study Group. Lancet. 1998;351:1153-1159.

18) Sensier YJ, Thrush AJ, Loftus I, et al. A comparison of colour duplex ultrasonography, papaverine testing and common femoral Doppler waveform analysis for assessment of the aortoiliac arteries. Eur J Vasc Endovasc Surg. 2000;20:29-35.

19) Vrolix M, Piessens J, De Geest H. Torsades de pointes after intracoronary papaberine. Eur Heart J. 1991;12:273-276.

20) Shryock JC, Belardinelli L. Adenosine and adenosine receptors in the cardiovascular system: biochemistry, physiology, and pharmacology. Am J Cardiol. 1997;79:2-10.

[Received December 22, 2017 : Accepted January 16, 2018] 